\title{
An Internet-Based Intervention for Depression in Primary Care in Spain: A Randomized Controlled Trial
}

Jesús Montero-Marín ${ }^{1,2,3}, \mathrm{PhD}$; Ricardo Araya ${ }^{4}$, MD, PhD; María C Pérez-Yus ${ }^{2,3,5}$, PhD; Fermín Mayoral ${ }^{2,6}$, MD, $\mathrm{PhD}$; Margalida Gili ${ }^{2,7}, \mathrm{MD}, \mathrm{PhD}$; Cristina Botella ${ }^{8,9}, \mathrm{PhD}$; Rosa Baños ${ }^{9,10}$, PhD; Adoración Castro ${ }^{2,7}$, PhD; Pablo Romero-Sanchiz $^{6}$, PhD; Yolanda López-Del-Hoyo ${ }^{2,3,11}$, PhD; Raquel Nogueira-Arjona ${ }^{12}$, PhD; Margarita Vives ${ }^{2,7}$, $\mathrm{MD}, \mathrm{PhD}$; Antoni Riera ${ }^{8}$, PhD; Javier García-Campayo ${ }^{2,3,13}, \mathrm{MD}, \mathrm{PhD}$



\section{Corresponding Author:}

María C Pérez-Yus, PhD

Aragon Health Sciences Institute

Avda. San Juan Bosco, 13. 50009. Zaragoza.

Zaragoza,

Spain

Phone: $34(+34) 976715895$

Fax: $34(+34) 976714670$

Email: mcperezy@gmail.com

\section{Abstract}

Background: Depression is the most prevalent cause of illness-induced disability worldwide. Face-to-face psychotherapeutic interventions for depression can be challenging, so there is a need for other alternatives that allow these interventions to be offered. One feasible alternative is Internet-based psychological interventions. This is the first randomized controlled trial (RCT) on the effectiveness of an Internet-based intervention on depression in primary health care in Spain.

Objective: Our aim was to compare the effectiveness of a low-intensity therapist-guided (LITG) Internet-based program and a completely self-guided (CSG) Internet-based program with improved treatment as usual (iTAU) care for depression.

Methods: Multicenter, three-arm, parallel, RCT design, carried out between November 2012 and January 2014, with a follow-up of 15 months. In total, 296 adults from primary care settings in four Spanish regions, with mild or moderate major depression, were randomized to LITG ( $n=96)$, CSG $(n=98)$, or iTAU $(n=102)$. Research completers at follow-up were $63.5 \%$. The intervention was Smiling is Fun, an Internet program based on cognitive behavioral therapy. All patients received iTAU by their general practitioners. Moreover, LITG received Smiling is Fun and the possibility of psychotherapeutic support on request by email, whereas CSG received only Smiling is Fun. The main outcome was the Beck Depression Inventory-II at 3 months from baseline. Mixed-effects multilevel analysis for repeated measures were undertaken.

Results: There was no benefit for either CSG $[(\mathrm{B}$ coefficient $=-1.15 ; P=.444)]$ or LITG $[(\mathrm{B}=-0.71 ; P=.634)]$ compared to iTAU, at 3 months. There were differences at 6 months [iTAU vs CSG $(B=-4.22 ; P=.007)$; iTAU vs LITG $(B=-4.34 ; P=.005)]$ and 15 
months [iTAU vs CSG $(\mathrm{B}=-5.10 ; P=.001)$; iTAU vs LITG $(\mathrm{B}=-4.62 ; P=.002)$ ]. There were no differences between $\mathrm{CSG}$ and LITG at any time. Adjusted and intention-to-treat models confirmed these findings.

Conclusions: An Internet-based intervention for depression combined with iTAU conferred a benefit over iTAU alone in the Spanish primary health care system.

Trial Registration: Clinicaltrials.gov NCT01611818; https://register.clinicaltrials.gov/prs/app/action/SelectProtocol? selectaction=Edit\&uid=U0001NPQ\&ts=2\&cx=gctdh2\&sid=S0003KJ6 (Archived by http://www.webcitation.org/6jbsUvUDz)

(J Med Internet Res 2016;18(8):e231) doi: 10.2196/jmir.5695

\section{Introduction}

Depression is the most prevalent cause of illness-induced disability worldwide [1]. It is among the most common reasons for consulting a general practitioner (GP), and it carries considerable personal and economic burden [2]. Antidepressants are a common form of treatment for depressive patients in primary care (PC) [3], but many patients would also like to receive psychotherapy [4]. Psychological treatments for depression are shown to be effective in PC, especially when GPs refer patients for treatment [5]. There is evidence that psychological treatments achieve results as effective as those achieved by antidepressant medication, reducing the number of physician consultations and hospital days, and obtaining better results in adherence, relapse prevention, and reducing chronicity [6].

Nevertheless, delivering face-to-face psychotherapeutic interventions to a population is challenging given the lack of specialized resources [7], so there is a need for other alternatives that allow these interventions to be offered. One feasible alternative is Internet-based psychological interventions [8]. The Internet offers a way of providing psychological treatments for depression [9] that may even attract people who are reluctant to use traditional mental health services [10] because of barriers such as possible stigmatization processes [11]. In general, Internet-based psychological treatments seem to be effective for the treatment of depression. Although the effects seem to be more favorable for guided or assisted interventions [12-14], stand-alone Internet-based treatments for depression have also shown to be effective [15].

Until now, there have been no studies on the effectiveness of Internet-based treatments for depression in the context of PC in Spain. Therefore, the main objective of this study was to compare the effectiveness of a low-intensity therapist-guided (LITG) Internet-based program and a completely self-guided (CSG) Internet-based program with improved treatment as usual (iTAU) care for the treatment of major depression in PC in Spain.

\section{Methods}

\section{Hypotheses}

The main hypothesis was that both Internet-based interventions, CSG and LITG, would be more effective in reducing depressive symptoms than iTAU, in the context of PC at 3 months after baseline. A secondary hypothesis was that, in the context of PC, where there is a more frequent and closer contact with the GPs, the offer of additional help is unlikely to improve outcomes when using Internet-based interventions.

\section{Design}

This study was a multicenter, three-arm, parallel, randomized controlled trial (RCT). Adults presenting with depressive symptoms in PC were randomized to receive either iTAU from their GP or an Internet-based intervention program (Smiling is Fun) for depression, in this case, either with psychotherapist support (LITG) or without it (CSG). The trial protocol of the study [16], the manual used to implement the program [17], and a study on expectations of depressed PC patients have already been published $[18,19]$.

\section{Recruitment of Participants and Baseline Assessment}

We recruited patients with major depression, aged 18-65 years, able to understand and read Spanish, with mild or moderate severity symptoms according to the Spanish Beck Depression Inventory-II (BDI-II) (14-19: mild depression; 20-28: moderate depression) [20], with symptoms lasting longer than 2 weeks, with access to Internet at home, and having an email account. Major depression was identified using the MINI International Neuropsychiatric Interview 5.0, which can establish major depression diagnoses according to the Diagnostic and Statistical Manual, version IV (DSM-IV) and International Classification of Diseases [21,22]. We excluded patients who had been receiving any psychological treatment during the previous year, those with severe psychiatric disorder in Axis I (eg, alcohol/substances abuse or dependence, psychotic disorders, dementia), and patients with severe depression (score $\geq 29$ on the BDI-II), who were referred by their GPs for treatment.

Participants were recruited in PC settings, between November 2012 and January 2014, in the Spanish regions of Aragon, Andalusia, the Balearic Islands, and Valencia. GPs identified potential participants through using a case-finding questionnaire. Eligible individuals were then interviewed in the clinic within the following 3 days by an independent researcher, who assessed inclusion and exclusion criteria, using the MINI psychiatric interview and other questionnaires. Informed consent to enter the trial was sought from patients who fulfilled study criteria, followed by randomization, carried out by an independent researcher. Patient safety was systematically monitored. The Ethical Review Board of the regional health authority approved the study on April 7, 2010 (ref: PI10/01083).

\section{Randomization, Concealment, and Blinding}

Participants were individually randomized using blocked randomization to one of the three groups. Blocks were administered in each of the regions, using a computer-generated 
random number sequence. A person who had no other involvement in the study managed the random allocation to groups. This procedure was implemented through a remote central telephone line. The sequence was concealed until all individuals had been randomized. Although patients were not informed of the group allocation, the nature of the intervention meant that it was virtually impossible to keep this completely blind. Study personnel conducting the outcome assessments were blind to the participants' allocation.

\section{Follow-Up}

Collection of follow-up data took place between March 2013 and June 2015. Participants were assessed online at 3 (time-1), 6 (time-2), and 15 (time-3) months post-baseline assessment. These moments deviated from the registered protocol. Post-treatment evaluation was stated at 3 months after the beginning of the intervention in order not to favor participants in the intervention conditions who could take longer than the estimated intervention duration comparing to control group. By setting the same evaluation moments for all participants, we ensured that measurements would be comparable. Participants were sent an email with a link to an online platform that hosted the questionnaires. No other protocols were used to increase compliance with the research data collection, but a phone call was made before each wave assessment to increase response rates.

\section{Control Group}

All the patients included in the study (whether in the control or intervention arms) received iTAU. This treatment was provided by their GPs, who had previously received a 3-hour training program to update their knowledge on how to diagnose and treat depression in primary care, based on the National Institute for Health and Care (NICE) guidelines [23]. The training mostly dealt with the appropriate use of antidepressants. In case of suicide risk or severe social dysfunction, or if worsening of symptoms was detected, patients were referred to mental health facilities.

\section{Intervention Groups}

Smiling is Fun is an Internet-delivered, self-help program for the treatment of depression, based on similar programs that have proven effective in other countries [24]. The program consists of 10 cognitive behavioral therapy modules, covering different psychological techniques for coping with depression. These modules need to be completed in a sequential way. The program recommends working on every module for at least a week, with the following modules: (1) Medication management (psychoeducation I), (2) Sleep hygiene (psychoeducation II), (3) Motivation for change (motivation), (4) Understanding emotional problems (psychoeducation III), (5) Learning to move on (behavioural activation), (6) Learning to be flexible (cognitive therapy), (7) Learning to enjoy (positive psychology I), (8) Learning to live (positive psychology II), (9) Living and learning (positive psychology III), and (10) From now on, what else? (relapse prevention). A more specific and detailed description of the module contents can be found elsewhere $[16,17]$.
Patients in the intervention groups were allocated to LITG or to CSG Internet-based programs. In LITG, 4 trained psychotherapists randomly contacted the patients by email to offer help with any difficulties or problems encountered when using the program. Patients could ask the psychotherapists questions or advice via email messages with a maximum of three contacts over the treatment period. They could also ask a technician for help to resolve problems of a technical nature. In CSG, there was no contact with any therapist, and only technical questions could be asked regarding the computer program.

To maximize adherence, if participants did not access the program for a week, they received an automated email encouraging them to use the program and to complete the tasks for each module. In addition, the program offered continuous feedback to the users on their progress via (1) a self-monitored activity report, providing feedback on how their mood was related to the activities performed, (2) the calendar, providing feedback about homework and tasks already completed, and (3) graphs and other feedback about activity levels, emotional distress, and negative and positive emotionality.

Among those patients on medication, GPs and patients were advised not to increase dosages in any of the three groups (iTAU, CSG, LITG), but decreasing medication was permitted.

\section{Instruments}

\section{Demographic Variables}

We gathered sociodemographic data such as age, sex, living with family or alone, level of studies (university vs secondary or less), employment (employed vs unemployed), and income according to national minimum wage, as well as clinical variables such as taking antidepressant medication (yes vs no) and the number of GP visits in the previous 12 months.

\section{Outcomes}

The Spanish version of BDI-II [19], as a continuous variable, was used as the primary outcome measure at time 1 (3 months after baseline). The BDI-II is one of the most widely used instruments to evaluate presence and severity of depressive symptoms. It is a self-reported measure, which includes the cardinal cognitive, emotional, and somatic symptoms of depression, and it can be linked to diagnosis from the DSM-IV. The studies published show good agreement between BDI-II and the clinical diagnosis of depression, and good psychometric properties for the scale $[25,26]$. Scores can range from 0-63.

Secondary outcomes included the visual analogue scale (VAS) of the EuroQol (EQ-5D) [27], in its Spanish version [28], and the Short Form Health Survey (SF-12v1) [29], in its Spanish version [30], as measures of health-related quality of life and functioning. The VAS is a vertical line on which the best and worst possible health states are scored 100 or zero respectively. The SF-12 scoring algorithm yields a physical component scale and a mental component scale, and both were used as continuous variables applying Spanish norms, with a mean of 50 (SD 10) [30]. 


\section{Sample Size}

Estimated sample size in protocol was 450 participants [16], but there were recruitment problems in one of the four participant regions, Valencia, where there were multiple stakeholders, so the recruitment was delayed for more than one year. In view of this, the steering committee of the project decided to rule out recruitment in that region, repeating the process of sample size calculation, according to the new situation. This new power calculation was based on testing differences between LITG Internet-based program and iTAU care alone, and we based our sample size estimation on an expected difference in the primary outcome of at least 0.5 standard deviation (SD) [14]. This size has been considered as a clinically relevant criterion [24,31]. Previous PC studies of depressed patients in England and Spain have found BDI-II means and SDs of 22 and 12, respectively, but as our inclusion cut-off points attenuate variability, we used an SD of 6 . Thus, a difference of 3 points across these two groups was our target (around 15\%). In order to detect this difference between LITG and iTAU, assuming a common SD of 6 points, a 5\% significance level and a statistical power of $80 \%$, we needed 63 subjects in each group. We expected a dropout rate of around $30 \%[12,32]$, so we inflated the numbers to reach a total sample size of around 300 patients (100 per arm). This change in the number of participants was more realistic for the new situation of recruitment.

\section{Data Analysis}

First, descriptive data were compared to assess the balance of a number of variables across arms at baseline. All analyses followed a pre-specified plan [16], based on the Consolidated Standards of Reporting Trial (CONSORT) guidelines [33] (Multimedia Appendix 1). The primary between-group analysis was carried out on an intention-to-treat basis for BDI-II total scores, using a multilevel mixed-effects analysis for repeated measures, and calculating regression coefficients (B), unadjusted and adjusted for baseline scores, sex, and age [34]. Sensitivity analyses were conducted to assess the effects of missing data. Missing values were replaced by multiple imputations based on chained equations, after ensuring that data were missing at random [35]. Secondary analysis comprised comparisons of SF-12 Mental and Physical subscale scores, as well as EuroQol VAS scores using the same analytical strategy. Effect sizes between groups were calculated by means of Hedge's $g$, and group by time interactions ( 3 groups and 4 time points) through chi-square tests, unadjusted and adjusted for baseline, sex, and age, with the associated degrees of freedom of (r-1) x (c-1), where $r$ is the number of groups and $c$ is the number of time points. We also performed a Complier Average Causal Effect (CACE) analysis to assess the impact of the number of sessions on the outcome. We theoretically defined compliance as attendance at $>6$ sessions, but we also performed a parallel assessment of the impact for each session added separately.

We used two-sided tests at the 5\% significance level, taking into account Bonferroni's criterion whenever there were multiple comparisons. All the analyses were performed with Stata 12.

\section{Results}

A total of 46 GPs took part in the study. Of 397 potential participants, 296 were randomized (see Figure 1), with 102 allocated to iTAU, 98 to the CSG, and 96 to the LITG. The randomized groups were well balanced in all variables at baseline (Table 1). Recruitment varied across regions: 126 participants from Aragon, 106 from Andalusia, 44 from the Balearic Islands, and 20 from Valencia. Follow-up primary outcome data were obtained for $239(80.7 \%)$ of the participants at Time 1, $210(70.9 \%)$ at Time 2, and 203 (68.6) at Time 3. There were no significant differences among groups in terms of attrition rate (iTAU $=34.3 \%$; $\mathrm{CSG}=41.8 \%$; $\mathrm{LITG}=33.3 \%$; $\chi_{2}^{2}=0.42 ; P=.812$ ). Only age was significantly related to attrition (at Time 3) [completers ( $\mathrm{n}=203)$ : mean 44.28 years (SD 10.22) vs missing ( $\mathrm{n}=93)$ : mean 39.99 years (SD 10.01); $P=.001]$. No baseline-level differences in other sociodemographic or primary or secondary outcomes were observed between completers and non-completers at different waves, so dropouts were considered as to be random [36]. The median depression severity across all groups in BDI-II at baseline was 23 , which broadly equated with a depression of moderate severity [20]. 
Table 1. Baseline characteristics of participants across groups.

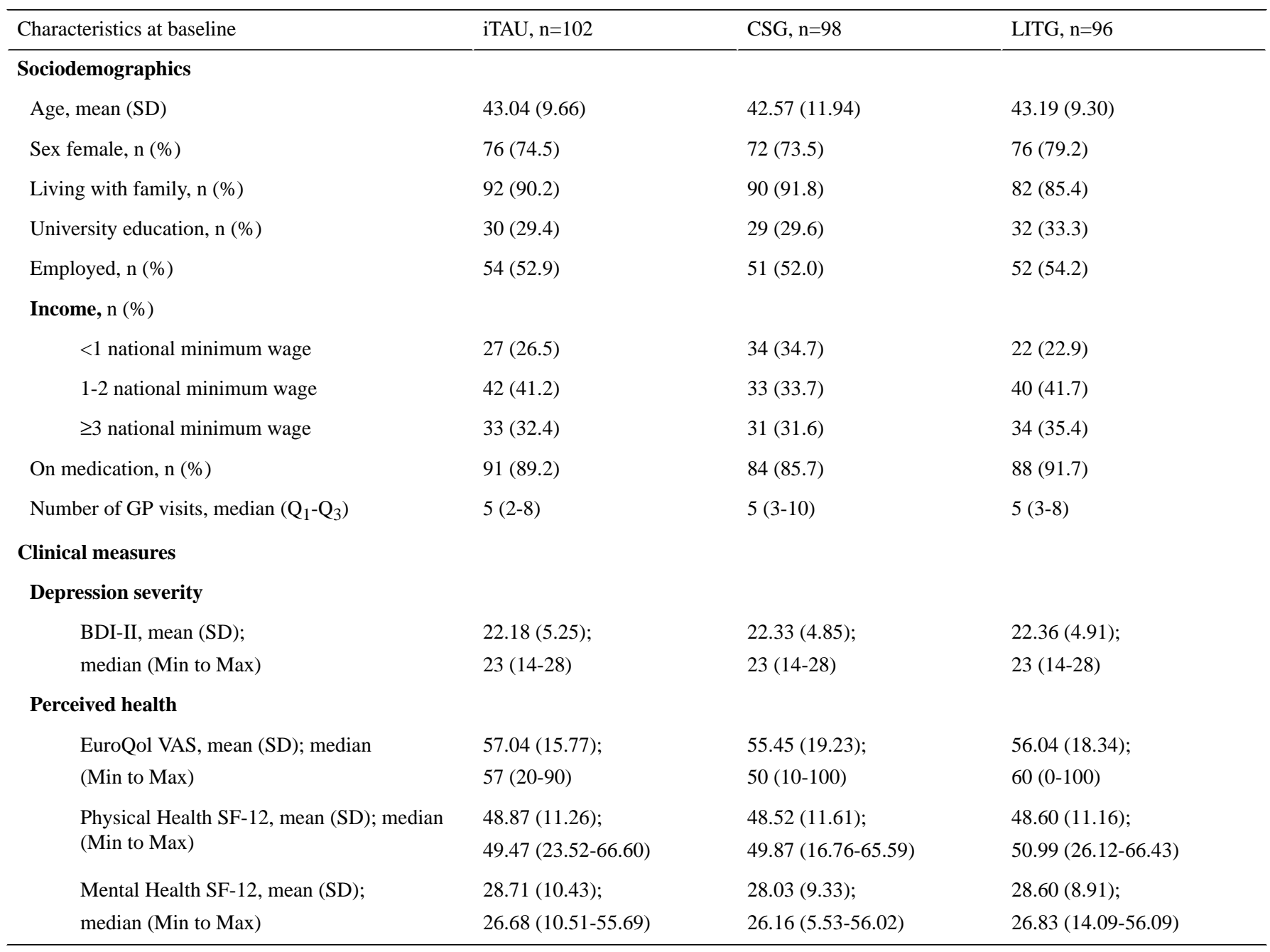


Figure 1. Flow diagram.

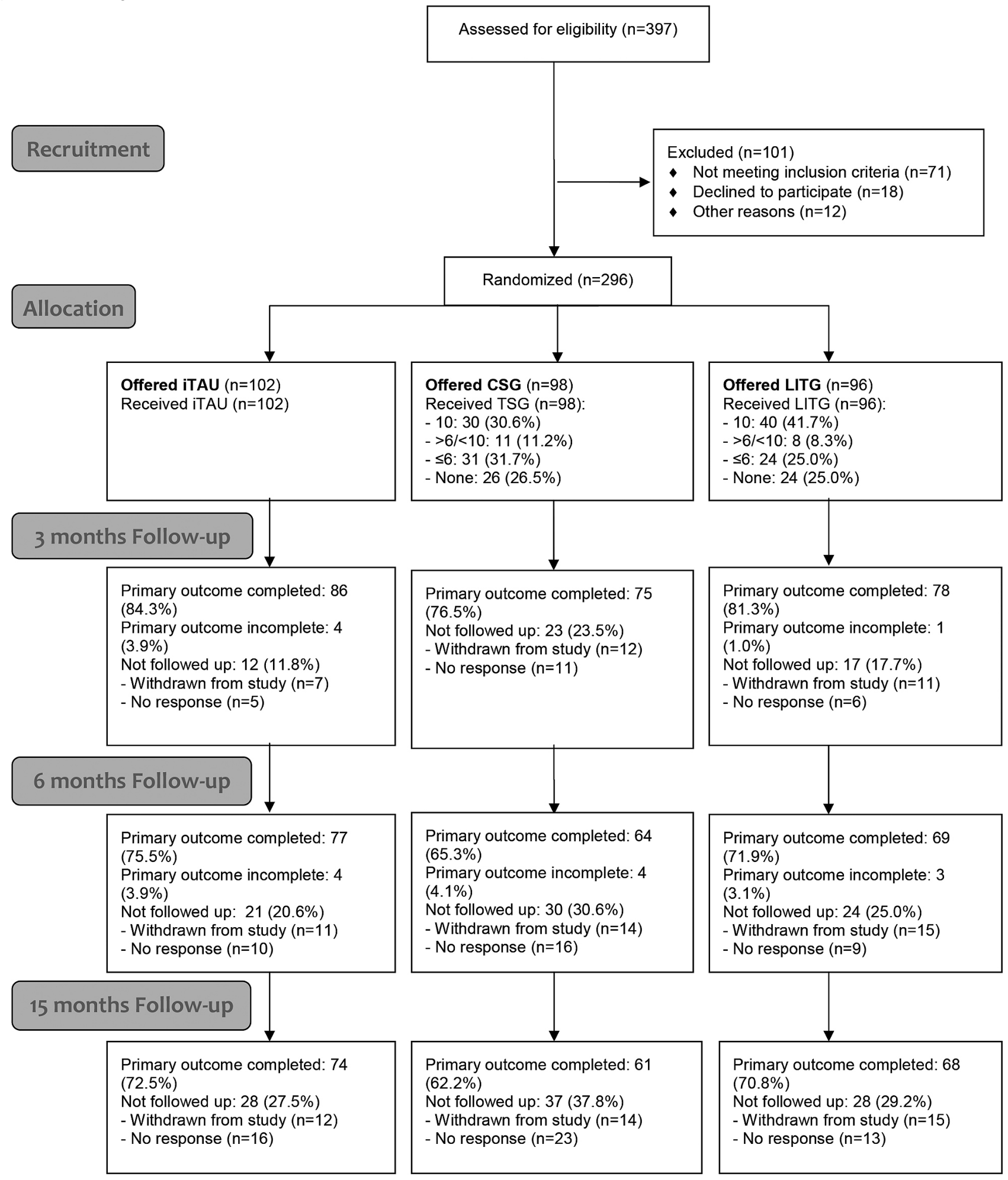

\section{Primary Analyses}

There were no clear differences between either CSG or LITG compared with iTAU at Time 1 (Table 2). However, there were differences between iTAU versus CSG, and iTAU versus LITG at Time 2 and at Time 3, with both computerized interventions performing better than usual care. There were no significant differences between CSG and LITG at any time. The adjusted models confirmed these findings (Table 2). Models with missing values replaced through multiple imputations showed small reductions in regression coefficients, but the main differences remained unaltered: Time 2 , iTAU vs CSG $(\mathrm{B}=-2.91 ; P<.001)$; iTAU vs LITG $(\mathrm{B}=-3.97 ; P<.001)$; Time 3 , iTAU vs $\mathrm{CSG}$ $(\mathrm{B}=-3.69 ; P<.001)$; iTAU vs LITG $(\mathrm{B}=-4.26 ; P<.001)$. In keeping with the above results, there was a significant group $\mathrm{x}$ time interaction (unadjusted: $\chi_{6}^{2}=19.23 ; P=.003$; adjusted: $\chi_{6}^{2}=21.27 ; P=.001$; imputed: $\left.\chi_{6}^{2}=343.16 ; P<.001\right)$. The CACE analysis and the estimated additional intervention effect per 
sessions attended also showed there was an additional benefit with more sessions attended (Table 4).

Table 2. Primary outcome analysis with observed data ${ }^{a}$.

\begin{tabular}{|c|c|c|c|c|c|c|c|c|c|c|c|c|}
\hline & $\begin{array}{l}\text { iTAU (a) } \\
\text { mean }(\mathrm{SD})\end{array}$ & $\begin{array}{l}\text { CSG }(b) \\
\text { mean }(S D)\end{array}$ & $\begin{array}{l}\text { LITG }(\mathrm{c}) \\
\text { mean }(\mathrm{SD})\end{array}$ & $\begin{array}{l}g \\
(a-b)\end{array}$ & $\begin{array}{l}P \\
\text { (a-b) }\end{array}$ & $\begin{array}{l}\text { B } \\
(95 \% \mathrm{CI}) \\
(\mathrm{a}-\mathrm{b})\end{array}$ & $\begin{array}{l}g \\
(a-c)\end{array}$ & $\begin{array}{l}P \\
(\mathrm{a}-\mathrm{c})\end{array}$ & $\begin{array}{l}\text { B } \\
(95 \% \mathrm{CI}) \\
(\mathrm{a}-\mathrm{c})\end{array}$ & $\begin{array}{l}g \\
(b-c)\end{array}$ & $\begin{array}{l}P \\
(\mathrm{~b}-\mathrm{c})\end{array}$ & $\begin{array}{l}\text { B } \\
(95 \% \mathrm{CI}) \\
(\mathrm{b}-\mathrm{c})\end{array}$ \\
\hline BDI-II & $\mathrm{n}=67$ & $\mathrm{n}=57$ & $\mathrm{n}=64$ & & & & & & & & & \\
\hline Time 0 & $\begin{array}{l}21.76 \\
(5.39)\end{array}$ & $\begin{array}{l}22.59 \\
(4.78)\end{array}$ & $\begin{array}{l}21.73 \\
(4.83)\end{array}$ & & & & & & & & & \\
\hline Time 1 & $\begin{array}{l}17.91 \\
(11.06)\end{array}$ & $\begin{array}{l}16.59 \\
(10.60)\end{array}$ & $\begin{array}{l}17.08 \\
(10.24)\end{array}$ & 0.12 & .444 & $\begin{array}{l}-1.15 \\
(-4.08 \\
\text { to } 1.79)\end{array}$ & 0.08 & .634 & $\begin{array}{l}-0.71 \\
(-3.61 \\
\text { to } 2.20)\end{array}$ & -0.05 & .764 & $\begin{array}{l}0.44 \\
(-2.45 \\
\text { to } 3.34)\end{array}$ \\
\hline Adjusted & & & & & .359 & $\begin{array}{l}-1.35 \\
(-4.23 \\
\text { to } 1.54)\end{array}$ & & .613 & $\begin{array}{l}-0.74 \\
(-3.60 \\
\text { to } 2.12)\end{array}$ & & .674 & $\begin{array}{l}0.61 \\
(-2.23 \\
\text { to } 3.45)\end{array}$ \\
\hline Time 2 & $\begin{array}{l}18.12 \\
(12.15)\end{array}$ & $\begin{array}{l}14.27 \\
(10.00)\end{array}$ & $\begin{array}{l}13.56 \\
(11.56)\end{array}$ & 0.34 & .007 & $\begin{array}{l}-4.22 \\
(-7.28 \\
\text { to }-1.16)\end{array}$ & 0.38 & .005 & $\begin{array}{l}-4.34 \\
(-7.36 \\
\text { to }-1.33)\end{array}$ & 0.07 & .938 & $\begin{array}{l}-0.12 \\
(-3.14 \\
\text { to } 2.90)\end{array}$ \\
\hline Adjusted & & & & & .003 & $\begin{array}{l}-4.55 \\
(-7.56 \\
\text { to }-1.55)\end{array}$ & & .004 & $\begin{array}{l}-4.31 \\
(-7.27 \\
\text { to }-1.35)\end{array}$ & & .862 & $\begin{array}{l}0.26 \\
(-2.70 \\
\text { to } 3.22)\end{array}$ \\
\hline Time 3 & $\begin{array}{l}16.72 \\
(10.97)\end{array}$ & $\begin{array}{l}11.53 \\
(10.72)\end{array}$ & $\begin{array}{l}11.39 \\
(10.96)\end{array}$ & 0.48 & .001 & $\begin{array}{l}-5.10 \\
(-8.20 \\
\text { to }-1.99)\end{array}$ & 0.48 & .003 & $\begin{array}{l}-4.62 \\
(-7.66 \\
\text { to }-1.58)\end{array}$ & 0.01 & .758 & $\begin{array}{l}0.48 \\
(-2.57 \\
\text { to } 3.54)\end{array}$ \\
\hline Adjusted & & & & & $<.001$ & $\begin{array}{l}-5.47 \\
(-8.51 \\
\text { to }-2.42)\end{array}$ & & .002 & $\begin{array}{l}-4.62 \\
(-7.61 \\
\text { to }-1.63)\end{array}$ & & .574 & $\begin{array}{l}0.86 \\
(-2.14 \\
\text { to } 3.85)\end{array}$ \\
\hline
\end{tabular}

a $g$ : Hedge's g as an effect size measure; B: regression coefficients; adjusted: adjusted analysis controlling baseline, sex, and age; a-b: iTAU vs CSG comparison; a-c: iTAU vs LITG comparison; b-c: CSG vs LITG comparison.

\section{Secondary Analyses}

Results with the Mental SF-12 showed a similar pattern of differences as in the primary outcome (Table 3). Analysis with imputed values attenuated coefficients but the main differences were maintained: Time 2, iTAU vs CSG ( $\mathrm{B}=4.79 ; P<.001)$; iTAU vs LITG $(\mathrm{B}=4.76 ; P<.001)$; Time 3 , ITAU vs $\mathrm{CSG}$ $(\mathrm{B}=4.63 ; P<.001)$; iTAU vs LITG $(\mathrm{B}=5.54 ; P<.001)]$. Similarly, group $\mathrm{x}$ time interactions were observed (unadjusted: $\chi_{6}^{2}=27.05$; $P<.001$; adjusted: $\chi_{6}^{2}=31.01 ; P<.001$; imputed: $\chi_{6}^{2}=422.56$; $P<.001)$, and there were also dose-response effects associated with the number of sessions (Table 4). There were no differences across arms for Physical SF-12 at any time (Table 3). Some differences were found between iTAU vs LITG at Time 2 and
Time 3 when using EUROQOL (Table 3), which were confirmed with adjusted and imputed models: imputed Time 1: $\mathrm{B}=2.49 ; P<.001$; Time 2: $\mathrm{B}=7.26 ; P<.001$; Time 3: $\mathrm{B}=7.66$; $P<.001$. At Time 3, there were also EUROQOL differences between iTAU vs CSG in the adjusted model. Using imputed data, these differences were also seen at earlier times (Time 2: $\mathrm{B}=3.78 ; P<.001$; Time 3 : $\mathrm{B}=5.30 ; P<.001)$. When imputing values, we also found differences between CSG vs LITG at Time $1(\mathrm{~B}=2.75 ; P<.001)$, Time $2(\mathrm{~B}=3.48 ; P<.001)$, and Time $3(\mathrm{~B}=2.35 ; P<.001)$. Group $\mathrm{x}$ time effects were not found with unadjusted data $\left(\chi_{6}^{2}=11.10 ; P=.085\right)$, but there were interactions with the adjusted $\left(\chi_{6}^{2}=12.88 ; P=.045\right)$ and imputed $\left(\chi_{6}^{2}=219.54\right.$; $P<.001)$ models. Dose-response effects were also found (Table $4)$. 
Table 3. Secondary outcome analyses with observed data $\mathrm{a}^{\mathrm{a}}$.

\begin{tabular}{|c|c|c|c|c|c|c|c|c|c|c|c|c|}
\hline & $\begin{array}{l}\text { iTAU (a) } \\
\text { mean (SD) }\end{array}$ & $\begin{array}{l}\text { CSG }(b) \\
\text { mean }(S D)\end{array}$ & $\begin{array}{l}\text { LITG }(\mathrm{c}) \\
\text { mean }(\mathrm{SD})\end{array}$ & $\begin{array}{l}g \\
(a-b)\end{array}$ & $\begin{array}{l}P \\
\text { (a-b) }\end{array}$ & $\begin{array}{l}\text { B }(95 \% \text { CI }) \\
(a-b)\end{array}$ & $\begin{array}{l}g \\
(\mathrm{a}-\mathrm{c})\end{array}$ & $\begin{array}{l}P \\
(\mathrm{a}-\mathrm{c})\end{array}$ & $\begin{array}{l}\text { B }(95 \% \text { CI }) \\
(a-c)\end{array}$ & $\begin{array}{l}g \\
(b-c)\end{array}$ & $\begin{array}{l}P \\
(\mathrm{~b}-\mathrm{c})\end{array}$ & $\begin{array}{l}\mathrm{B}(95 \% \mathrm{CI}) \\
(\mathrm{b}-\mathrm{c})\end{array}$ \\
\hline Mental SF-12 & $\mathrm{n}=64$ & $\mathrm{n}=55$ & $\mathrm{n}=64$ & & & & & & & & & \\
\hline Time 0 & $\begin{array}{l}29.13 \\
(11.18)\end{array}$ & $\begin{array}{l}28.59 \\
(8.90)\end{array}$ & $\begin{array}{l}27.95 \\
(8.78)\end{array}$ & & & & & & & & & \\
\hline Time 1 & $\begin{array}{l}35.41 \\
(12.19)\end{array}$ & $\begin{array}{l}34.72 \\
(12.46)\end{array}$ & $\begin{array}{l}36.97 \\
(12.57)\end{array}$ & 0.06 & .380 & $\begin{array}{l}-1.83 \\
(-5.91 \\
\text { to } 2.25)\end{array}$ & -0.13 & .682 & $\begin{array}{l}0.85 \\
(-3.20 \\
\text { to } 4.89)\end{array}$ & -0.18 & .216 & $\begin{array}{l}2.63 \\
(-1.54 \\
\text { to } 6.80)\end{array}$ \\
\hline Adjusted & & & & & .341 & $\begin{array}{l}-1.94 \\
(-5.94 \\
\text { to } 2.06)\end{array}$ & & .589 & $\begin{array}{l}1.10 \\
(-2.87 \\
\text { to } 5.06)\end{array}$ & & .187 & $\begin{array}{l}3.01 \\
(-1.06 \\
\text { to } 7.07)\end{array}$ \\
\hline Time 2 & $\begin{array}{l}36.05 \\
(12.38)\end{array}$ & $\begin{array}{l}42.35 \\
(11.03)\end{array}$ & $\begin{array}{l}42.22 \\
(13.24)\end{array}$ & -0.53 & .003 & $\begin{array}{l}6.49 \\
(2.26 \\
\text { to } 10.72)\end{array}$ & -0.48 & .005 & $\begin{array}{l}5.97 \\
(1.80 \\
\text { to } 10.13)\end{array}$ & 0.01 & .801 & $\begin{array}{l}-0.56 \\
(-4.89 \\
\text { to } 3.78)\end{array}$ \\
\hline Adjusted & & & & & .002 & $\begin{array}{l}6.67 \\
(2.53 \\
\text { to } 10.81)\end{array}$ & & .002 & $\begin{array}{l}6.41 \\
(2.33-10.49)\end{array}$ & & .863 & $\begin{array}{l}-0.37 \\
(-4.59 \\
\text { to } 3.85)\end{array}$ \\
\hline Time 3 & $\begin{array}{l}36.35 \\
(12.12)\end{array}$ & $\begin{array}{l}43.44 \\
(11.66)\end{array}$ & $\begin{array}{l}43.65 \\
(13.41)\end{array}$ & -0.59 & .002 & $\begin{array}{l}6.78 \\
(2.46 \\
\text { to } 11.11)\end{array}$ & -0.57 & .003 & $\begin{array}{l}6.53 \\
(2.29 \\
\text { to } 10.76)\end{array}$ & -0.02 & .901 & $\begin{array}{l}-0.28 \\
(-4.69 \\
\text { to } 4.12)\end{array}$ \\
\hline Adjusted & & & & & .001 & $\begin{array}{l}7.03 \\
(2.80 \\
\text { to } 11.26)\end{array}$ & & .001 & $\begin{array}{l}7.09 \\
(2.95 \\
\text { to } 11.24)\end{array}$ & & .989 & $\begin{array}{l}-0.03 \\
(-4.31 \\
\text { to } 4.25)\end{array}$ \\
\hline $\begin{array}{l}\text { Physical SF- } \\
12\end{array}$ & $\mathrm{n}=64$ & $\mathrm{n}=55$ & $\mathrm{n}=64$ & & & & & & & & & \\
\hline Time 0 & $\begin{array}{l}48.74 \\
(11.67)\end{array}$ & $\begin{array}{l}47.83 \\
(12.29)\end{array}$ & $\begin{array}{l}47.98 \\
(10.87)\end{array}$ & & & & & & & & & \\
\hline Time 1 & $\begin{array}{l}47.91 \\
(10.31)\end{array}$ & $\begin{array}{l}48.84 \\
(11.89)\end{array}$ & $\begin{array}{l}49.20 \\
(10.58)\end{array}$ & -0.08 & .443 & $\begin{array}{l}1.13 \\
(-1.76-4.02)\end{array}$ & -0.12 & .638 & $\begin{array}{l}0.69 \\
(-2.17-3.54)\end{array}$ & -0.03 & .760 & $\begin{array}{l}-0.44 \\
(-3.26- \\
2.38)\end{array}$ \\
\hline Adjusted & & & & & .382 & $\begin{array}{l}1.23 \\
(-1.53-4.00)\end{array}$ & & .542 & $\begin{array}{l}0.85 \\
(-1.89-3.60)\end{array}$ & & .799 & $\begin{array}{l}-0.35 \\
(-3.02- \\
2.33)\end{array}$ \\
\hline Time 2 & $\begin{array}{l}47.56 \\
(10.74)\end{array}$ & $\begin{array}{l}47.42 \\
(12.18)\end{array}$ & $\begin{array}{l}46.87 \\
(10.79)\end{array}$ & 0.01 & .820 & $\begin{array}{l}0.35 \\
(-2.66 \\
\text { to } 3.35)\end{array}$ & 0.06 & .906 & $\begin{array}{l}-0.18 \\
(-3.13 \\
\text { to } 2.77)\end{array}$ & 0.05 & .727 & $\begin{array}{l}-0.52 \\
(-3.46- \\
2.41)\end{array}$ \\
\hline Adjusted & & & & & .677 & $\begin{array}{l}0.61 \\
(-2.26 \\
\text { to } 3.47)\end{array}$ & & .946 & $\begin{array}{l}0.10 \\
(-2.72 \\
\text { to } 2.92)\end{array}$ & & .727 & $\begin{array}{l}-0.49 \\
(-3.27- \\
2.28)\end{array}$ \\
\hline Time 3 & $\begin{array}{l}47.53 \\
(11.78)\end{array}$ & $\begin{array}{l}47.65 \\
(11.89)\end{array}$ & $\begin{array}{l}48.05 \\
(9.85)\end{array}$ & -0.01 & .864 & $\begin{array}{l}0.27 \\
(-2.81 \\
\text { to } 3.34)\end{array}$ & -0.05 & .655 & $\begin{array}{l}0.68 \\
(-2.32 \\
\text { to } 3.68)\end{array}$ & -0.04 & .781 & $\begin{array}{l}0.42 \\
(-2.56 \\
\text { to } 3.41)\end{array}$ \\
\hline Adjusted & & & & & .830 & $\begin{array}{l}0.32 \\
(-2.61 \\
\text { to } 3.25)\end{array}$ & & .620 & $\begin{array}{l}0.73 \\
(-2.14 \\
\text { to } 3.59)\end{array}$ & & .755 & $\begin{array}{l}0.45 \\
(-2.37 \\
\text { to } 3.27)\end{array}$ \\
\hline $\begin{array}{l}\text { EuroQol } \\
\text { VAS }\end{array}$ & $\mathrm{n}=66$ & $\mathrm{n}=57$ & $\mathrm{n}=65$ & & & & & & & & & \\
\hline Time 0 & $\begin{array}{l}57.80 \\
(15.81)\end{array}$ & $\begin{array}{l}53.56 \\
(20.05)\end{array}$ & $\begin{array}{l}57.46 \\
(18.23)\end{array}$ & & & & & & & & & \\
\hline
\end{tabular}




\begin{tabular}{|c|c|c|c|c|c|c|c|c|c|c|c|c|}
\hline & $\begin{array}{l}\text { iTAU (a) } \\
\text { mean }(\mathrm{SD})\end{array}$ & $\begin{array}{l}\text { CSG }(b) \\
\text { mean }(S D)\end{array}$ & $\begin{array}{l}\text { LITG }(\mathrm{c}) \\
\text { mean }(\mathrm{SD})\end{array}$ & $\begin{array}{l}g \\
(\mathrm{a}-\mathrm{b})\end{array}$ & $\begin{array}{l}P \\
(\mathrm{a}-\mathrm{b})\end{array}$ & $\begin{array}{l}\text { B (95\% CI) } \\
(a-b)\end{array}$ & $\begin{array}{l}g \\
(\mathrm{a}-\mathrm{c})\end{array}$ & $\begin{array}{l}P \\
(\mathrm{a}-\mathrm{c})\end{array}$ & $\begin{array}{l}\text { B }(95 \% \text { CI }) \\
(a-c)\end{array}$ & $\begin{array}{l}g \\
(b-c)\end{array}$ & $\begin{array}{l}P \\
(b-c)\end{array}$ & $\begin{array}{l}\mathrm{B}(95 \% \mathrm{CI}) \\
(\mathrm{b}-\mathrm{c})\end{array}$ \\
\hline Time 1 & $\begin{array}{l}62.12 \\
(18.12)\end{array}$ & $\begin{array}{l}63.11 \\
(21.61)\end{array}$ & $\begin{array}{l}65.85 \\
(21.34)\end{array}$ & $\begin{array}{c}-0.05 \\
\end{array}$ & .924 & $\begin{array}{l}0.30 \\
(-5.91 \\
\text { to } 6.52)\end{array}$ & -0.19 & .418 & $\begin{array}{l}2.55 \\
(-3.61 \\
\text { to } 8.70)\end{array}$ & $\begin{array}{c}-0.13 \\
\end{array}$ & .495 & $\begin{array}{l}2.24 \\
(-4.19 \\
\text { to } 8.66)\end{array}$ \\
\hline Adjusted & & & & & .816 & $\begin{array}{l}0.71 \\
(-5.32 \\
\text { to } 6.75)\end{array}$ & & .385 & $\begin{array}{l}2.66 \\
(-3.33 \\
\text { to } 8.64)\end{array}$ & & .541 & $\begin{array}{l}1.94 \\
(-4.28 \\
\text { to } 8.17)\end{array}$ \\
\hline Time 2 & $\begin{array}{l}62.33 \\
(20.83)\end{array}$ & $\begin{array}{l}65.81 \\
(21.44)\end{array}$ & $\begin{array}{l}69.83 \\
(20.21)\end{array}$ & -0.16 & .152 & $\begin{array}{l}4.73 \\
(-1.73 \\
\text { to } 11.19)\end{array}$ & -0.36 & .016 & $\begin{array}{l}7.73 \\
(1.38 \\
\text { to } 14.09)\end{array}$ & -0.19 & .381 & $\begin{array}{l}2.99 \\
(-3.70 \\
\text { to } 9.68)\end{array}$ \\
\hline Adjusted & & & & & .088 & $\begin{array}{l}5.45 \\
(-0.81 \\
\text { to } 11.71)\end{array}$ & & .013 & $\begin{array}{l}7.84 \\
(1.68 \\
\text { to } 14.01)\end{array}$ & & .478 & $\begin{array}{l}2.34 \\
(-4.13 \\
\text { to } 8.81)\end{array}$ \\
\hline Time 3 & $\begin{array}{l}62.59 \\
(20.37)\end{array}$ & $\begin{array}{l}68.89 \\
(22.79)\end{array}$ & $\begin{array}{l}72.45 \\
(15.93)\end{array}$ & -0.29 & .028 & $\begin{array}{l}7.39 \\
(0.82 \\
\text { to } 13.97)\end{array}$ & -0.54 & .014 & $\begin{array}{l}8.10 \\
(1.65 \\
\text { to } 14.54)\end{array}$ & -0.18 & .842 & $\begin{array}{l}0.69 \\
(-6.09 \\
\text { to } 7.47)\end{array}$ \\
\hline Adjusted & & & & & .011 & $\begin{array}{l}8.31 \\
(1.94 \\
\text { to } 14.44)\end{array}$ & & .010 & $\begin{array}{l}8.19 \\
(1.95 \\
\text { to } 14.44)\end{array}$ & & .970 & $\begin{array}{l}-0.13 \\
(-6.68 \\
\text { to } 6.43)\end{array}$ \\
\hline
\end{tabular}

${ }^{a}$ : Hedge's g as an effect size measure; B: regression coefficients; adjusted: adjusted analysis controlling baseline, sex, and age; a-b: iTAU vs CSG comparison; a-c: iTAU vs LITG comparison; b-c: CSG vs LITG comparison.

Table 4. Dose-response in primary and secondary outcomes.

\begin{tabular}{|c|c|c|c|c|c|c|}
\hline \multirow[t]{2}{*}{ Variables } & \multicolumn{2}{|l|}{$\operatorname{Raw}^{\mathrm{a}}$} & \multicolumn{2}{|l|}{ Adjusted $^{\mathrm{b}}$} & \multicolumn{2}{|l|}{ Imputed $^{\mathrm{c}}$} \\
\hline & B & $P$ & B & $P$ & B & $P$ \\
\hline \multicolumn{7}{|l|}{ BDI-II } \\
\hline CACE analysis ${ }^{\mathrm{d}}$ & $-6.93(-12.52$ to -1.33$)$ & .016 & $-7.24(-12.33$ to -2.15$)$ & .006 & $-8.07(-9.42$ to -6.72$)$ & $<.001$ \\
\hline Effect per session & $-0.65(-1.18$ to -0.13$)$ & .015 & $-0.68(-1.16$ to -0.20$)$ & .006 & $-0.73(-0.85$ to -0.61$)$ & $<.001$ \\
\hline \multicolumn{7}{|l|}{ Mental SF-12 } \\
\hline CACE analysis ${ }^{\mathrm{d}}$ & $9.42(3.08$ to 15.75$)$ & .004 & 10.27 (4.01 to 16.52$)$ & .001 & $10.59(9.05$ to 12.12$)$ & $<.001$ \\
\hline Effect per session & $0.89(0.29$ to 1.48$)$ & .004 & 0.97 (0.38 to 1.56$)$ & .001 & 0.95 (0.82 to 1.09$)$ & $<.001$ \\
\hline \multicolumn{7}{|l|}{ Physical SF-12 } \\
\hline CACE analysis ${ }^{\mathrm{d}}$ & $0.01(-5.71$ to 5.74$)$ & .996 & $0.65(-3.85$ to 5.16$)$ & .776 & $0.29(-1.07$ to 1.64$)$ & .676 \\
\hline Effect per session & $<1.01(-0.54$ to 0.54$)$ & .996 & $0.06(-0.36$ to 0.49$)$ & .775 & $0.03(-0.10$ to 0.15$)$ & .676 \\
\hline \multicolumn{7}{|l|}{ EuroQol VAS } \\
\hline CACE analysis ${ }^{\mathrm{d}}$ & 11.44 (0.76 to 22.12$)$ & .036 & 12.18 (2.22 to 22.13$)$ & .017 & $13.12(10.58$ to 15.66$)$ & $<.001$ \\
\hline Effect per session & 1.08 (0.08 to 2.07$)$ & .034 & 1.15 (0.22 to 2.07$)$ & .016 & $1.18(0.96$ to 1.41$)$ & $<.001$ \\
\hline
\end{tabular}

\footnotetext{
${ }^{\mathrm{a}}$ Using raw models.

${ }^{\mathrm{b}}$ Adjusting baseline, sex and age.

${ }^{\mathrm{c}}$ Using imputed data.

${ }^{\mathrm{d}}$ Compliance as attendance at $>6$ sessions. B: regression coefficients. Controls were considered as receiving 0 sessions.
}

\section{Internet-Based Program Usage}

At Time 3, 72.4\% ( $n=71)$ of CSG participants and $75.0 \%(n=72)$ of LITG participants had accessed the Internet-based programs $\left(\chi_{1}^{2}=0.35 ; P=.556\right)$. In CSG, the median number of modules completed was 4 (interquartile range: $0-10$ ), with $41.8 \%$ attending $>6$ modules; 30 participants in this group completed sessions. In LITG, the median number of modules completed 
was 6 (interquartile range: 0 -10), with $50.0 \%$ attending $>6$ modules and 40 participants completing 10 modules. There was no significant difference between CSG and LTIG in terms of modules completed $(\mathrm{Z}=-1.20 ; P=.228)$. A total of 17 email contacts were made with 13 participants of the LITG program, which represented $11.9 \%$ of the patients in this group. Support requests were monitored, and a content analysis of them showed that the topics were related to (1) requesting information on depressive symptoms, (2) counseling with regard to events and difficulties in life, and (3) additional support to follow the program recommendations. As per protocol, CSG received no email contact from therapists.

\section{Other Treatments Received}

Most of the participants received drug treatment (Table 1). There were no major differences in the use of medication (as a dichotomous criterion of drug intake) across groups (iTAU: 80.6\%; CSG: $68.3 \%$; LITG: $\left.67.6 \% ; \chi_{2}^{2}=3.67 ; P=.160\right)$. The same pattern was found for the use of mental health services, psychiatrist and/or psychologist (iTAU: 29.9\%; CSG: 19.7\%; LITG: $\left.18.8 \% ; \chi_{2}^{2}=3.09 ; P=.214\right)$, and number of visits to the GP [iTAU: median=2 $\left(\mathrm{Q}_{1}=0 ; \mathrm{Q}_{3}=4\right)$; $\mathrm{CSG}$ : median $=1\left(\mathrm{Q}_{1}=0\right.$; $\left.\mathrm{Q}_{3}=3\right)$; LITG: median $\left.=1\left(\mathrm{Q}_{1}=0 ; \mathrm{Q}_{3}=4\right) ; \chi_{2}^{2}=0.22 ; P=.643\right]$.

\section{Discussion}

\section{Principal Findings}

As far as we are aware, this is the first RCT on the effectiveness of an Internet-based intervention for the treatment of depression in PC health services in Spain. Other Web-based interventions for treating depressive symptoms in the Spanish language have been developed in Mexico [37] and Chile [38], but the efficacy of these interventions in reducing depressive symptoms has not yet been evaluated in an RCT. Therefore, this trial is novel in that it allowed the testing of a new Spanish program (Smiling is Fun), which adapted some of the techniques used in other available programs [24,39]. This trial compared two Internet-based interventions, with and without psychotherapeutic support, with usual care. We observed differences in the medium and long term in favor of psychotherapy, but not in the short term. This was somewhat consistent with previous studies on depression when comparing face-to-face psychotherapy (alone or plus usual care), with usual care based on medication treatments [40]. We found a larger effect size than in previous works, particularly in the group without additional support, and we also found that the offer of support did not yield additional benefits in terms of better adherence or outcomes, contrary to other previously published studies $[41,42]$.

The way patients were recruited in PC settings, with face-to-face contacts in a confidential context with the involvement of the GP, might explain why our results were better than those of other trials [14]. Studies in which patients suffering from depression were referred by their GP for treatment had generally shown higher effect sizes, with values similar to our study [5]. This aspect of the trial may have also contributed to the low number of email contacts requesting assistance to the psychotherapists, and therefore, to the similarity in the results for the supported and the unsupported groups. This same result has also been found in other works [15], although effect sizes in Internet-based interventions with therapist support typically seem larger than those without therapist support [14]. In our study, the type of support received by email on request was less intense than in other efficacy trials, which additionally include a group with some kind of weekly contact $[14,15]$. Patients in our study did not make much use of the support offered. We do not know the real reasons for this, but the lack of initial face-to-face contact with the psychotherapist might have hampered the establishment of an adequate alliance-something that might merit interest for further studies [19].

The possibility of receiving attention and care from a GP in a PC setting could also help minimize the stigma associated with referral to mental health services [11] and could improve adherence to the program. In fact, our procedure was as close as possible to the usual practice, and thus, it might increase the likelihood that the program might be used in the PC health services in Spain, where most depressed patients are treated [43]. Nevertheless, GPs may experience difficulties in recruiting patients because of their overloaded schedule, as has been described in other countries [44].

\section{Limitations}

This study encountered several limitations. First, attrition at follow-up was significant, but replacing missing values through imputations confirmed the main findings. As shown in other similar trials of computerized interventions, attrition rates are often large [12,32]. If anything, our retention rate was probably as good, if not better, than that achieved in other similar trials. Second, the potential effect of GPs or psychotherapist was not taken into account and may have been a source of variability. Finally, this trial was not powered to detect small differences between the two computerized interventions. This part of the study needs to be tested properly in a separate trial also controlling for the possible effects of psychotherapists and GPs.

\section{Conclusions}

A Spanish-language Internet-based intervention for the treatment of depression (Smiling is Fun) added to usual care proved to be more effective than treatment as usual alone at follow-up assessments. Pending cost-effectiveness analysis, these results suggest that it might be worth investing in this program for PC clinics in Spain, and possibly in other Spanish-speaking settings. The kind of low-intensity support offered in the program did not show additional improvement on the effectiveness of the computerized intervention. It remains to be seen whether or not any other forms of online/telephone support might yield further gains.

\section{Acknowledgments}

This study was financed by the Instituto de Salud Carlos III of the Spanish Ministry of Economy and Competitiveness with the PI10/01083 grant (Eficacia y coste-efectividad de un programa de psicoterapia asistida por ordenador para el tratamiento de la 
depresión mayor en atención primaria: estudio controlado, randomizado y cualitativo). The project also received funding from the Network for Prevention and Health Promotion in primary Care (RD12/0005) grant from the Instituto de Salud Carlos III of the Ministry of Economy and Competitiveness (Spain), co-financed with European Union ERDF funds.

\section{Conflicts of Interest}

None declared.

\section{Multimedia Appendix 1}

CONSORT-EHEALTH checklist V1.6.1 [33].

[PDF File (Adobe PDF File), 7MB-Multimedia Appendix 1]

\section{References}

1. Richards D. Prevalence and clinical course of depression: a review. Clin Psychol Rev 2011 Nov;31(7):1117-1125. [doi: 10.1016/j.cpr.2011.07.004] [Medline: 21820991]

2. Ustün TB, Ayuso-Mateos JL, Chatterji S, Mathers C, Murray CJL. Global burden of depressive disorders in the year 2000. Br J Psychiatry 2004 May;184:386-392 [FREE Full text] [Medline: 15123501]

3. Mohr DC, Ho J, Duffecy J, Baron KG, Lehman KA, Jin L, et al. Perceived barriers to psychological treatments and their relationship to depression. J Clin Psychol 2010 Apr;66(4):394-409 [FREE Full text] [doi: 10.1002/jclp.20659] [Medline: 20127795]

4. Lester H, Howe A. Depression in primary care: three key challenges. Postgrad Med J 2008 Oct;84(996):545-548. [doi: 10.1136/pgmj.2008.068387] [Medline: 19017840]

5. Cuijpers P, van SA, van SA, Andersson G. Psychological treatment of depression in primary care: a meta-analysis. Br J Gen Pract 2009 Feb;59(559):e51-e60 [FREE Full text] [doi: 10.3399/bjgp09X395139] [Medline: 19192368]

6. Huhn M, Tardy M, Spineli LM, Kissling W, Förstl H, Pitschel-Walz G, et al. Efficacy of pharmacotherapy and psychotherapy for adult psychiatric disorders: a systematic overview of meta-analyses. JAMA Psychiatry 2014 Jun;71(6):706-715. [doi: 10.1001/jamapsychiatry.2014.112] [Medline: 24789675]

7. Bower P, Gilbody S. Stepped care in psychological therapies: access, effectiveness and efficiency. Narrative literature review. Br J Psychiatry 2005 Jan;186:11-17 [FREE Full text] [doi: 10.1192/bjp.186.1.11] [Medline: 15630118]

8. Whiteside U, Richards J, Steinfeld B, Simon G, Caka S, Tachibana C, et al. Online cognitive behavioral therapy for depressed primary care patients: a pilot feasibility project. Perm J 2014 May;18(2):21-27 [FREE Full text] [doi: 10.7812/TPP/13-155] [Medline: 24867546]

9. van BW, Cuijpers P, van SA, Karyotaki E, Andersson G, Smit JH, et al. Adherence to Internet-based and face-to-face cognitive behavioural therapy for depression: a meta-analysis. PLoS One 2014 Jul;9(7):e100674 [FREE Full text] [doi: 10.1371/journal.pone.0100674] [Medline: 25029507]

10. Cuijpers P, van SA, Warmerdam L, van Rooy MJ. Recruiting participants for interventions to prevent the onset of depressive disorders: possible ways to increase participation rates. BMC Health Serv Res 2010;10:181 [FREE Full text] [doi: 10.1186/1472-6963-10-181] [Medline: 20579332]

11. Ellis LA, Collin P, Hurley PJ, Davenport TA, Burns JM, Hickie IB. Young men's attitudes and behaviour in relation to mental health and technology: implications for the development of online mental health services. BMC Psychiatry 2013;13:119 [FREE Full text] [doi: 10.1186/1471-244X-13-119] [Medline: 23601273]

12. Andersson G, Cuijpers P. Internet-based and other computerized psychological treatments for adult depression: a meta-analysis. Cogn Behav Ther 2009 Dec;38(4):196-205. [doi: 10.1080/16506070903318960] [Medline: 20183695]

13. Spek V, Cuijpers P, Nyklícek I, Riper H, Keyzer J, Pop V. Internet-based cognitive behaviour therapy for symptoms of depression and anxiety: a meta-analysis. Psychol Med 2007 Mar;37(3):319-328. [doi: 10.1017/S0033291706008944] [Medline: 17112400$]$

14. Kleiboer A, Donker T, Seekles W, van SA, Riper H, Cuijpers P. A randomized controlled trial on the role of support in Internet-based problem solving therapy for depression and anxiety. Behav Res Ther 2015 Sep;72:63-71. [doi: 10.1016/j.brat.2015.06.013] [Medline: 26188373]

15. Berger T, Hämmerli K, Gubser N, Andersson G, Caspar F. Internet-based treatment of depression: a randomized controlled trial comparing guided with unguided self-help. Cogn Behav Ther 2011 Dec;40(4):251-266. [doi: 10.1080/16506073.2011.616531] [Medline: 22060248]

16. López-del-Hoyo Y, Olivan B, Luciano JV, Mayoral F, Roca M, Gili M, et al. Low intensity vs. self-guided internet-delivered psychotherapy for major depression: a multicenter, controlled, randomized study. BMC Psychiatry 2013;13:21 [FREE Full text] [doi: 10.1186/1471-244X-13-21] [Medline: 23312003]

17. Botella C, Garcia-Palacios A, Banos R, Quero S. Tratamiento psicológico de la depresión: aplicación presencial y online. Editorial Síntesis 2016:-. 
18. Montero-Marín J, Carrasco JM, Roca M, Serrano-Blanco A, Gili M, Mayoral F, et al. Expectations, experiences and attitudes of patients and primary care health professionals regarding online psychotherapeutic interventions for depression: protocol for a qualitative study. BMC Psychiatry 2013;13:64 [FREE Full text] [doi: 10.1186/1471-244X-13-64] [Medline: 23425435]

19. Montero-Marín J, Prado-Abril J, Botella C, Mayoral-Cleries F, Baños R, Herrera-Mercadal P, et al. Expectations among patients and health professionals regarding Web-based interventions for depression in primary care: a qualitative study. J Med Internet Res 2015 Mar;17(3):e67 [FREE Full text] [doi: 10.2196/jmir.3985] [Medline: 25757358]

20. Sanz J, García-Vera M, Espinosa R, Fortún M, Vázquez C. Adaptación española del Inventario para la Depresión de Beck-II (BDI-II): 3. Propiedades psicométricas en pacientes con trastornos psicológicos. Clínica y salud 2005;16(2):3.

21. Ferrando L, Bobes J, Gibert J, Soto M, Soto O. Mini-International Neuropsychiatric Interview (Versión en Español 5.0). Madrid: IAP; 1998.

22. Lecrubier Y, Sheehan D, Weiller E. The Mini International Neuropsychiatric Interview (MINI). A short diagnostic structured interview: reliability and validity according to the CIDI. European Psychiatry 1997;12(5):224-231.

23. García-Herrera J, Nogueras-Morillas V, Muñoz-Cobos F, Morales-Asensio J. Guía de Práctica Clínica para el tratamiento de la depresión en Atención Primaria Clinical Practice Guide on the Treatment of Depression in Primary Care. Málaga: GAEDAP; 2011. URL: http://www.guiasalud.es/GPC/GPC 488 Depresion AP resum.pdf [accessed 2016-08-12] [WebCite Cache ID 6jhxGQ4kx]

24. Purves DG, Bennett M, Wellman N. An open trial in the NHS of Blues Begone: a new home based computerized CBT program. Behav Cogn Psychother 2009 Oct;37(5):541-551. [doi: 10.1017/S1352465809990282] [Medline: 19703330]

25. Beck A, Steer R. BDI-II - Beck Depression Inventory Manual. Second Volume. San Antonio: The Psychological Corporation; 1996.

26. Schotte CK, Maes M, Cluydts R, De DD, Cosyns P. Construct validity of the Beck Depression Inventory in a depressive population. J Affect Disord 1997 Nov;46(2):115-125. [Medline: 9479615]

27. EuroQol Group. EuroQol--a new facility for the measurement of health-related quality of life. Health Policy 1990;16(3):199-208.

28. Badia X, DeCharro F. EuroQol, un instrumento para valorar la salud. EQ 5-D guía del usuario (Spanish version). Med Clin 1999;114:6-14.

29. Ware JJ, Kosinski M, Keller S. A 12-Item Short-Form Health Survey: construction of scales and preliminary tests of reliability and validity. Med Care 1996 Mar;34(3):220-233. [Medline: 8628042]

30. Vilagut G, Ferrer M, Rajmil L. El cuestionario de salud SF-36 español: una década de experiencia y nuevos desarrollos. Gaceta sanitaria 2005;19(2):135-150.

31. Cavanagh K, Shapiro DA, Van Den Berg S, Swain S, Barkham M, Proudfoot J. The effectiveness of computerized cognitive behavioural therapy in routine care. Br J Clin Psychol 2006 Nov;45(Pt 4):499-514. [doi: 10.1348/014466505X84782] [Medline: 17076960 ]

32. Kaltenthaler E, Parry G, Beverley C, Ferriter M. Computerised cognitive-behavioural therapy for depression: systematic review. Br J Psychiatry 2008 Sep;193(3):181-184 [FREE Full text] [doi: 10.1192/bjp.bp.106.025981] [Medline: 18757972]

33. Eysenbach G, Consort-EHEALTH Group. CONSORT-EHEALTH: improving and standardizing evaluation reports of Web-based and mobile health interventions. J Med Internet Res 2011;13(4):e126 [FREE Full text] [doi: 10.2196/jmir.1923] [Medline: 22209829]

34. Egbewale BE, Lewis M, Sim J. Bias, precision and statistical power of analysis of covariance in the analysis of randomized trials with baseline imbalance: a simulation study. BMC Med Res Methodol 2014;14:49 [FREE Full text] [doi: 10.1186/1471-2288-14-49] [Medline: 24712304]

35. White IR, Royston P, Wood AM. Multiple imputation using chained equations: Issues and guidance for practice. Stat Med 2011 Feb 20;30(4):377-399. [doi: 10.1002/sim.4067] [Medline: 21225900]

36. National Research Council (US) Panel on Handling Missing Data in Clinical Trials. The Prevention and Treatment of Missing Data in Clinical Trials. Washington, DC: National Academies Press; 2010.

37. Lara M, Tiburcio M, Aguilar A, Sánchez-Solís A. A four-year experience with a Web-based self-help intervention for depressive symptoms in Mexico. Rev Panam Salud Publica 2014;35:398-406.

38. Espinosa H, Carrasco A, Moessner M, Cáceres C, Gloger S, Rojas G, et al. Acceptability Study of "Ascenso": An Online Program for Monitoring and Supporting Patients with Depression in Chile. Telemed J E Health 2016 Jul;22(7):577-583. [doi: 10.1089/tmj.2015.0124] [Medline: 26741190]

39. Marks IM, Cavanagh K, Gega L. Computer-aided psychotherapy: revolution or bubble? Br J Psychiatry 2007 Dec;191:471-473 [FREE Full text] [doi: 10.1192/bjp.bp.107.041152] [Medline: 18055948]

40. Spielmans GI, Berman MI, Usitalo AN. Psychotherapy versus second-generation antidepressants in the treatment of depression: a meta-analysis. J Nerv Ment Dis 2011 Mar;199(3):142-149. [doi: 10.1097/NMD.0b013e31820caefb] [Medline: 21346483]

41. Johansson R, Andersson G. Internet-based psychological treatments for depression. Expert Rev Neurother 2012 Jul;12(7):861-869; quiz 870. [doi: 10.1586/ern.12.63] [Medline: 22853793]

42. Richards D, Richardson T. Computer-based psychological treatments for depression: a systematic review and meta-analysis. Clin Psychol Rev 2012 Jun;32(4):329-342. [doi: 10.1016/j.cpr.2012.02.004] [Medline: 22466510] 
43. Høifødt RS, Lillevoll KR, Griffiths KM, Wilsgaard T, Eisemann M, Waterloo K, et al. The clinical effectiveness of web-based cognitive behavioral therapy with face-to-face therapist support for depressed primary care patients: randomized controlled trial. J Med Internet Res 2013 Aug;15(8):e153 [FREE Full text] [doi: 10.2196/jmir.2714] [Medline: 23916965]

44. Fernández A, Saameño JAB, Pinto-Meza A, Luciano JV, Autonell J, Palao D, et al. Burden of chronic physical conditions and mental disorders in primary care. Br J Psychiatry 2010 Apr;196(4):302-309 [FREE Full text] [doi:

10.1192/bjp.bp.109.074211] [Medline: 20357307]

\title{
Abbreviations
}

BDI-II: Beck Depression Inventory-II

CACE: Complier Average Causal Effect

CSG: completely self-guided Internet-based program

DSM-IV: Diagnostic and Statistical Manual, version IV

GP: general practitioner

iTAU: improved treatment as usual care

LITG: low-intensity therapist-guided Internet-based program

PC: primary care

RCT: randomized controlled trial

SF-12: Short Form Health Survey

\author{
Edited by G Eysenbach; submitted 26.02.16; peer-reviewed by N Görg, D Richards, D Meyer; comments to author 24.03.16; revised \\ version received 26.04.16; accepted 23.06.16; published 26.08.16 \\ Please cite as: \\ Montero-Marín J, Araya R, Pérez-Yus MC, Mayoral F, Gili M, Botella C, Baños R, Castro A, Romero-Sanchiz P, López-Del-Hoyo \\ $Y$, Nogueira-Arjona R, Vives M, Riera A, García-Campayo J \\ An Internet-Based Intervention for Depression in Primary Care in Spain: A Randomized Controlled Trial \\ $J$ Med Internet Res 2016;18(8):e231 \\ URL: http://www.jmir.org/2016/8/e231/ \\ doi: 10.2196/jmir.5695 \\ PMID: 27565118
}

CJesús Montero-Marín, Ricardo Araya, María C Pérez-Yus, Fermín Mayoral, Margalida Gili, Cristina Botella, Rosa Baños, Adoración Castro, Pablo Romero-Sanchiz, Yolanda López-Del-Hoyo, Raquel Nogueira-Arjona, Margarita Vives, Antoni Riera, Javier García-Campayo. Originally published in the Journal of Medical Internet Research (http://www.jmir.org), 26.08.2016. This is an open-access article distributed under the terms of the Creative Commons Attribution License (http://creativecommons.org/licenses/by/2.0/), which permits unrestricted use, distribution, and reproduction in any medium, provided the original work, first published in the Journal of Medical Internet Research, is properly cited. The complete bibliographic information, a link to the original publication on http://www.jmir.org/, as well as this copyright and license information must be included. 